\title{
Biomedical Engineering or Biomedical Optics: Will the Real Discipline Please Stand Up?
}

\author{
Brian W Pogue
}




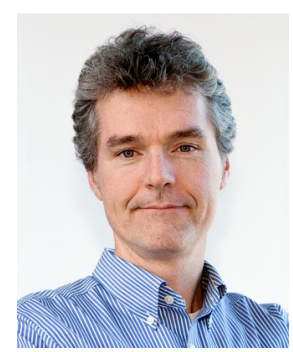

\section{Biomedical Engineering or Biomedical Optics: Will the Real Discipline Please Stand Up?}

While biomedical engineering (BME) has become the most competitive major in many of our highest engineering schools, it is still common to find that the narrative and behavior of those within this discipline do not match the features of a cohesive discipline. Many students, faculty, and employers within BME still cannot exactly pin down what it encompasses at its core, and what it represents in terms of academic training, nor its exact translational role in the world of products.

Ask any BME faculty member about their professional affiliation to BME as a discipline, and almost all will indicate that their real society affiliation is with the disease or organ site that they study (i.e., cancer, cardiology, neuroscience, etc.) or with the devices that they use (i.e., optics, x-rays, tissue engineering, biomaterials, patch clamps, imaging systems, etc.). This is readily seen from webpages from most BME faculty. Comparatively few will indicate that they primarily affiliate with a biomedical engineering society. This will be followed by the sheepish admission that they should really be more involved with a biomedical engineering society or meeting because it is good for the department. However, they indicate that the depth of specialization within BME societies is insufficient for their work.

Ask any student at the undergraduate level in BME, and they will indicate an exceptionally high allegiance to their BME department. In most major research universities it is one of the hardest majors to get acceptance to. The students are self-selected for the highest, type-A individuals with extreme academic achievement and capability. However, then ask them if they would like to be a biomedical engineer, and it is common to find that a minority of those will want to actually enter the workforce this way. The majority want to go to medical school or go on to higher education degrees, or work in consulting or other professions. This dichotomy is further complicated by employers in the biomedical industry, who often indicate that engineering generalists are not who they want hire. Rather, they higher specialists in electrical, mechanical, or computer systems, who can contribute in a deep way to their company goals and have an expertise base that they can understand. The disconnected nature of the

C 2019 Society of Photo-Optical Instrumentation Engineers (SPIE) pipeline of BME graduates with the workforce and the status of the field is puzzling.

We need to compare this with the deep cumulative experience offered in a technology-based biomedical engineering experience such as biomedical optics. Here are some posed questions and thoughts about the answers.

\section{Where does the field of biomedical engineering actually exist?}

The challenge around understanding this topic is that faculty who are problem-focused around medicine need a home, and making their home in a clinical or basic science department at a medical school puts them in a powerless situation without advocacy at the leadership level. Similarly, placing them in a traditional physical-science based engineering discipline takes away their translation potential and shifts the focus off of medical utility. Most faculty members will happily align within a BME department because it provides a home for outstanding researchers who seek to impact medicine with their engineering skillset. So the creation of biomedical engineering as a discipline has created a natural advocacy conduit for the faculty solving the problems of medicine. This home is superior to most experiences in clinical departments where the engineer may not be highly valued by a clinically driven department head.

\section{What message is given to students and the outside world about the field of BME?}

Biomedical engineering appears as wrapper from within which faculty can operate and identify themselves, but actually they really identify with their specialty area which is more technology driven or healthcare application driven. While BME has become the major success story of most engineering schools, drawing funding and media successes in a nearly unparalleled manner, it is not homogeneous, nor are there large synergies between neighboring faculty within a single department. To be sure, most BME faculty in large programs are not even housed in the same building or even the same campus area, because they prefer to exist close to their area of specialty rather than as a single faculty within an academic building.

Given that the field is more of a gathering point for collection of faculty and students, the real question is: does this illusion present any harm? Given the statistics of some of the highest GPA scores in students entering BME departments, and their apparent successes in following their chosen path, it cannot be all that harmful. Indeed, a good comparator is the pathway of liberal arts training at many undergraduate colleges being an outstanding preparation for life after a bachelor's degree for many students. Even though they will not spend their life calling themselves a liberal arts person, they exercise their brain in this pathway for four years and graduate having high intellectual engagement and are much better off from this nonparochial training. Students choose transdisciplinary pathways for two reasons, because they reject the need to stovepipe themselves and crave intellectual inquiry and discovery. They also see it as a competitive path, in the best colleges, where they will meet like-minded people and have an educational experience that stimulates them at the core of what they care about. BME appears to have become the analogous path to this within the engineering school system, at the undergraduate level, appealing 
primarily to those who are predisposed to healthcare as a vocation or a driving influence. Further, industry leaders know that the quality of education is superseded by the quality of the individual; so in terms of job potential, it is the individual that matters and not the educational path that they have chosen.

BME is an outstanding broad based education platform in which students grow up, developing a logical, quantitative and medical framework. They may not necessarily spend their lives calling themselves biomedical engineers, nor will they always be hired based upon this, but they can do this if they choose to. Clearly biomedical companies develop products and smart engineers are needed to make this happen. As long as the students are high achievers and use this education platform for their benefit, it all works out well, as with any educational program.

\section{Do biomedical engineering societies provide real cohesion?}

The impact of societies built around BME seems to be less certain than the field itself. The allegiance to each other is uncertain, and the prestige of the society does not seem to match the prestige of the departments nor the students that they purport to represent. So one must question if the national and international field representation is on mark, or simply is a rallying point around some outstanding individuals. At least the core of BME represents excellence, and one day the outer representation of it may match the inner quality, if the logistics of what the field actually is can be worked out.

BME boldly projects the core principle of the discipline to translate engineering facts and methods into actionable medical practice. The self-driven researchers within BME choose to think differently about medicine and engineering and how to educate themselves. BME researchers transcend the boundaries of both engineering and medicine, which leads to a way of thinking about BME as not really a single society or discipline but rather like a viral spread that is not easily recognized. The virus is not a single entity but rather a collection of smartly encoded entities which each infect by the same
DNA each invading a single host cell, ultimately changing the behavior of the whole organism. But still the technical specialty and the scientific growth of any individual in BME is often about their tool or biological application and not about the wider field of BME.

\section{How does biomedical optics fit within biomedical engineering?}

The technology of optics is deep and wide, and those who choose to be experts in its use must have significant scientific training and research experience in the field. The range of devices and techniques that can be used is enormous, and as previously published, optics is the largest single technology sector in medicine. ${ }^{1}$ SPIE and the Journal of Biomedical Optics provide scientific connection points and conduits for exchanging research results among peer BME scientists and learning for scholars new to the field. ${ }^{2}$ The allegiance to the Photonics West BiOS conference and the commitment to publish in SPIE proceedings and journals is clearly visible by the large growth in numbers of submissions. Additionally, if you ask a new or experienced BME optics researcher in this field what their core expertise base is, you will uniformly get the same type of answer, which is that they use the technology of optics or photonics for measuring, diagnosing, or providing therapy to some biomedical need or healthcare application. This is the community that our journal serves, and it is a society that provides cohesion and exchange and growth in technical depth to its members.

\section{Brian W Pogue Editor-in-Chief}

\section{References}

1. B.W. Pogue and B.C. Wilson, "Optical and x-ray technology synergies enabling diagnostic and therapeutic applications in medicine," J. Biomed. Opt. 23(12), 121610 (2018).

2. B. W. Pogue, "Biomedical optics scientific community," J. Biomed. Opt. 23(1), 010101 (2018). 